\title{
The role of inhibitory associations in perceptual learning
}

\author{
C. H. BENNETT, V. L. SCAHILL, D. P. GRIFFITHS, and N. J. MACKINTOSH \\ University of Cambridge, Cambridge, England
}

\begin{abstract}
Preexposure to two compound flavors (AX and BX) typically enhances their discriminability: An aversion conditioned to $\mathrm{AX}$ will generalize less to $\mathrm{BX}$, especially if the preexposure regime has involved alternated presentations of $\mathrm{AX}$ and $\mathrm{BX}$ rather than presenting all $\mathrm{AX}$ trials before $\mathrm{BX}$ trials (or vice versa). One possible explanation of this finding is that alternating preexposure establishes inhibitory associations between the two unique features $\mathrm{A}$ and $\mathrm{B}$, thus counteracting the generalization produced by excitatory associations between $X$ and $A$ and between $X$ and $B$, which might result in either the retrieval of $\mathrm{B}$ on a conditioning trial to $\mathrm{AX}$, or the retrieval of $\mathrm{A}$ on a test trial to $\mathrm{BX}$. Three experiments on flavor aversion conditioning in rats tested these predictions. Experiment 1 suggested that the more important of these excitatory associations was that which allowed $\mathrm{X}$ to retrieve $\mathrm{A}$ on the test trial to BX. Experiment 2 suggested that the more important inhibitory association was that which allowed B to inhibit the representation of $\mathrm{A}$ on this test trial. Experiment 3 provided direct evidence of the role of this inhibitory $\mathrm{B} \dashv \mathrm{A}$ association.
\end{abstract}

Discrimination between two or more complex stimuli is often enhanced by prior exposure to one or more of them (see Hall, 1991, for a review). Such perceptual learning effects have been well established in flavor aversion conditioning, where discrimination between compound flavors such as mixtures of sucrose-lemon and saline-lemon is enhanced by exposure to one or both of these flavors prior to conditioning an aversion to one and testing generalization to the other (see, e.g., Bennett, Wills, Wells, \& Mackintosh, 1994; Mackintosh, Kaye, \& Bennett, 1991; Symonds \& Hall, 1995).

Mackintosh et al. (1991) showed that this perceptual learning effect was dependent on the use of compound flavors sharing an element or feature in common. If an aversion was conditioned to saline alone, it did not generalize strongly to sucrose, and prior exposure to saline and sucrose did nothing to reduce the generalization that did occur. This is hardly surprising. According to one popular account, generalization between two stimuli occurs to the extent that they share elements in common (Estes, 1950). If we represent two compound stimuli sharing elements in common as $\mathrm{AX}$ and $\mathrm{BX}$, where $\mathrm{A}$ and $\mathrm{B}$ are the elements unique to each stimulus, and $\mathrm{X}$ are those common to both, then conditioning to $\mathrm{AX}$ will generalize to $\mathrm{BX}$ because some of that conditioning accrues to the $X$ elements shared by BX. There is, moreover, a very simple reason why preexposure to two compound stimuli, $\mathrm{AX}$ and $\mathrm{BX}$, should reduce generalization between them (McLaren,

This research was supported by a grant from the Biotechnology and Biological Sciences Research Council to N.J.M., C.H.B., and I. P. L. McLaren. Correspondence concerning this article should be addressed to C. H. Bennett, Department of Experimental Psychology, University of Cambridge, Downing Street, Cambridge CB2 3EB, England (e-mail: chb22@cus.cam.ac.uk).
Kaye, \& Mackintosh, 1989). One of the best established consequences of preexposure to a stimulus that subsequently serves as the conditional stimulus (CS) in a conditioning experiment is a retardation of subsequent conditioning to that stimulus - the phenomenon of latent inhibition (Lubow, 1989). But preexposure to both AX and $\mathrm{BX}$ will ensure twice as much preexposure to $\mathrm{X}$ as to $\mathrm{A}$ and B. It seems probable, therefore, that such preexposure should result in more latent inhibition to $\mathrm{X}$ than to $\mathrm{A}$ when $\mathrm{AX}$ is paired with a reinforcer, and if conditioning now accrues preferentially to A at X's expense, there will be less basis for generalization to BX. There is, indeed, good evidence that such differential latent inhibition of common and unique elements contributes to the perceptual learning effects observed in flavor aversion conditioning (Bennett et al., 1994; Mackintosh et al., 1991).

There is equally good evidence, however, that differential latent inhibition cannot be the sole cause of such perceptual learning effects. One observation that points to this conclusion is the focus of our present concern. Symonds and Hall (1995) found that alternating or intermixed preexposure to two compound flavors, $\mathrm{AX}$ and $\mathrm{BX}$, resulted in less generalization from AX to BX (i.e., a stronger perceptual learning effect) than did a "blocked" preexposure regime, in which all preexposure to $\mathrm{AX}$ preceded that to $\mathrm{BX}$, or vice versa. Since both groups received exactly the same total amount of preexposure to $\mathrm{AX}$ and $\mathrm{BX}$, there is no reason to expect any difference between them in the amount of latent inhibition to $X$; and in a replication of Symonds and Hall's results, Bennett and Mackintosh (in press) confirmed that, although alternating and blocked groups differed in the extent to which an aversion conditioned to AX generalized to BX, they did not differ in the strength of conditioning to $\mathrm{X}$. What is the explanation of these results? Since alternating and blocked preexposure 
do not produce any difference in the strength of conditioning to the common element, $X$, there must be some other source of generalization between $\mathrm{AX}$ and $\mathrm{BX}$ operating in the blocked condition but not in the alternating condition. What might this be?

According to standard associative theory (e.g., McLaren et al., 1989), exposure to $A X$ and $B X$ will initially result in the formation of excitatory associations between $A$ and $X$, and between $B$ and $X$ elements, since they are always presented concurrently (for evidence of such withincompound flavor-flavor associations, see Rescorla \& Cunningham, 1978). These excitatory associations may reasonably be assumed to provide an additional source of generalization between $\mathrm{AX}$ and $\mathrm{BX}$, since the presentation of $\mathrm{AX}$ will now retrieve a representation of $\mathrm{B}$, and the presentation of $\mathrm{BX}$ a representation of $\mathrm{A}$. If we assume that such within-compound associations provided an additional source of generalization between $A X$ and $B X$ in the blocked condition of the Symonds and Hall (1995) and Bennett and Mackintosh (in press) studies, the question then arises what served to prevent this generalization in the alternating condition?

According to McLaren et al.(1989), although a small amount of preexposure to AX and BX will result in the formation of within-compound excitatory associations, prolonged alternating exposure to $\mathrm{AX}$ and $\mathrm{BX}$ will eventually result in the formation of inhibitory associations between $A$ and $B$, which will counteract the effects of $X$ 's excitatory associations with $\mathrm{A}$ and $\mathrm{B}$. On an $\mathrm{AX}$ preexposure trial, for example, the presence of $X$ will retrieve or activate B elements, but although B is thus expected, A actually predicts its absence. These are exactly the conditions necessary for the formation of inhibitory associations in Pavlovian conditioning (see, e.g., Rescorla, 1969). During blocked exposure, where all AX trials precede BX trials, there is no sense in which A elements predict the absence of otherwise expected $\mathrm{B}$ elements. Although $B$ may predict the absence of A during the second half of blocked exposure to BX, any inhibitory associations between $\mathrm{A}$ and $\mathrm{B}$ would most probably be weaker following blocked exposure than following alternating exposure. Alternating exposure to $\mathrm{AX}$ and $\mathrm{BX}$ should therefore establish mutually inhibitory associations between A and B, and according to McLaren et al., it is these inhibitory associations that counteract any generalization between $A X$ and $B X$ caused by both A and B's being associated with $\mathrm{X}$.

If we (provisionally) accept the argument so far, two further, related, questions may be asked. Blocked preexposure to $\mathrm{AX}$ and $\mathrm{BX}$ may result in the formation of excitatory associations between $X$ and $A$ and between $X$ and $B$. But which of these associations is the more important source of additional generalization to $\mathrm{BX}$ of an aversion conditioned to AX? And the related question is this: If alternating preexposure to $\mathrm{AX}$ and $\mathrm{BX}$ results in the formation of mutually inhibitory associations between $A$ and $\mathrm{B}$, which of these is the more important in counteracting this additional generalization between $\mathrm{AX}$ and $\mathrm{BX}$ ?

Consider the first question. There is, in fact, evidence that both the association between $\mathrm{X}$ and $\mathrm{A}$ and that between $X$ and $B$ might enhance generalization between $A X$ and BX. In a study of mediated, or representation-based conditioning, Holland (1981) showed that if an association was established between an auditory stimulus and a flavor, then subsequent pairing of the auditory stimulus with lithium-induced illness resulted in the establishment of an aversion to the flavor. In the context of the experimental procedures we are talking of here, the implication is that on a conditioning trial to $\mathrm{AX}$, if $\mathrm{X}$ retrieves a representation of $\mathrm{B}$, an aversion will also be conditioned to B. The phenomenon of backward sensory preconditioning also provides evidence of such a mechanism (WardRobinson \& Hall, 1996): Here, initial sequential pairing of $S 1$ and $S 2$, followed by the pairing of S1 with a reinforcer, is sufficient to establish conditioning to $S 2-$ presumably because $S 1$ retrieves a representation of $S 2$ on the conditioning trial. But backward sensory preconditioning is usually less effective than forward sensory preconditioning (Brogden, 1939; Brown \& King, 1969; Coppock, 1958; Prewitt, 1967; Tait, Marquis, Williams, Weinstein, \& Suboski, 1969), where after initial pairing of S1 and S2, $\mathrm{S} 2$ is conditioned and S1 finally tested. The standard explanation of forward sensory preconditioning is that, on test, $\mathrm{S} 1$ retrieves a representation of $\mathrm{S} 2$ which elicits the conditioned response. In the context of the present experimental procedures, the implication is that after conditioning to $\mathrm{AX}$, the presentation of $\mathrm{BX}$ on test retrieves (via $\mathrm{X})$ a representation of $\mathrm{A}$ which adds to the conditioned responding controlled by $\mathrm{X}$.

If forward sensory preconditioning is normally a more robust phenomenon than backward, the implication for our purposes is that X's retrieval of A on the test trial to $\mathrm{BX}$ is a more important source of generalization between $\mathrm{AX}$ and $\mathrm{BX}$ than is X's retrieval of $\mathrm{B}$ on the conditioning trial to AX. Experiment 1 in fact confirmed this expectation, and set the stage for Experiment 2.

If the main reason why blocked preexposure produces generalization between $\mathrm{AX}$ and $\mathrm{BX}$ is that $\mathrm{X}$ retrieves a representation of $\mathrm{A}$ on the test trial to $\mathrm{BX}$, it should follow that the main reason why alternating preexposure reduces this generalization is that $B$ inhibits the retrieval of A on this test trial. In other words, in terms of the McLaren et al. (1989) analysis, the more important of the mutually inhibitory associations between $\mathrm{A}$ and $\mathrm{B}$ established by alternating preexposure to $\mathrm{AX}$ and $\mathrm{BX}$ is that from $\mathrm{B}$ to $\mathrm{A}$ rather than that from $A$ to $B$. In Experiment 2, we devised two special preexposure regimes designed to establish unidirectional inhibitory associations, one from $A$ to $B$, the other from B to A. As expected, the second of these was more effective than the first in reducing generalization between AX and BX. Finally, Experiment 3 provided an alternative, more direct test of the extent to which these two 
Table 1

Design of Experiments 1, 2, and 3

\begin{tabular}{llll}
\hline Group & \multicolumn{1}{c}{ Preexposure } & Conditioning & Test \\
\cline { 2 - 3 } & \multicolumn{2}{c}{ Experiments $1 \mathrm{~A}$ and $1 \mathrm{~B}$} \\
$\mathrm{AX}$ & $\mathrm{AX}, \mathrm{B}, \mathrm{X}$ & $\mathrm{AX}+$ & $\mathrm{BX}$ \\
$\mathrm{BX}$ & $\mathrm{BX}, \mathrm{A}, \mathrm{X}$ & $\mathrm{AX}+$ & $\mathrm{BX}$ \\
$\mathrm{CONT}$ & $\mathrm{A}, \mathrm{B}, \mathrm{X}$ & $\mathrm{AX}+$ & $\mathrm{BX}$ \\
& \multicolumn{2}{c}{ Experiments $2 \mathrm{~A}$ and $2 \mathrm{~B}$} \\
$\mathrm{AX} \rightarrow \mathrm{BX}$ & $\mathrm{AX} \rightarrow \mathrm{BX}$ & $\mathrm{AX}+$ & \\
$\mathrm{BX} \rightarrow \mathrm{AX}$ & $\mathrm{BX} \rightarrow \mathrm{AX}$ & $\mathrm{AX}+$ & $\mathrm{BX}, \mathrm{X}$ \\
$\mathrm{BLK}$ & $\mathrm{AX} \ldots \mathrm{BX} \ldots$ & $\mathrm{AX}+$ & $\mathrm{BX}, \mathrm{X}$ \\
& $\mathrm{BX} \ldots \mathrm{AX} \ldots$ & & $\mathrm{BX}, \mathrm{X}$
\end{tabular}

Experiments $3 \mathrm{~A}$ and $3 \mathrm{~B}$

$\begin{array}{lllcc} & & & \text { Retardation } & \text { Extinction } \\ \mathrm{AX} \rightarrow \mathrm{BX} & \mathrm{AX} \rightarrow \mathrm{BX} & \mathrm{A}+ & \mathrm{B}+ & \mathrm{B} \\ \mathrm{BX} \rightarrow \mathrm{AX} & \mathrm{BX} \rightarrow \mathrm{AX} & \mathrm{A}+ & \mathrm{B}+ & \mathrm{B} \\ \mathrm{ALT} & \mathrm{AX} / \mathrm{BX} & \mathrm{A}+ & \mathrm{B}+ & \mathrm{B} \\ \mathrm{BLK} & \mathrm{AX} \ldots \mathrm{BX} \ldots & \mathrm{A}+ & \mathrm{B}+ & \mathrm{B}\end{array}$

Experiment 3C

\begin{tabular}{lllll}
$\mathrm{AX} \rightarrow \mathrm{BX}$ & $\mathrm{AX} \rightarrow \mathrm{BX}$ & $\mathrm{A}+$ & $\mathrm{Q}+$ & Summation \\
$\mathrm{BX} \rightarrow \mathrm{AX}$ & $\mathrm{BX} \rightarrow \mathrm{AX}$ & $\mathrm{A}^{+}$ & $\mathrm{Q}^{+}$ & $\mathrm{BQ}$ vs. Q \\
\hline
\end{tabular}

Note-Experiment $1 \mathrm{~A}$ contained all three groups; Experiment $1 \mathrm{~B}$ omitted Group CONT. Experiment 3A included all four groups; Experiment 3B omitted Group ALT. A, sucrose; B, saline; X, lemon; Q, quinine; + , lithium chloride

preexposure regimes did actually result in unidirectional inhibitory associations between $\mathrm{A}$ and $\mathrm{B}$.

\section{EXPERIMENT 1}

Experiment 1 was designed to test the notion that in addition to the strength of conditioning to the common element $X$, the other major source of generalization to BX of an aversion conditioned to $\mathrm{AX}$ is $\mathrm{X}$ 's retrieval of $\mathrm{A}$ when $B X$ is presented on test, rather than X's retrieval of $\mathrm{B}$ during conditioning trials with $\mathrm{AX}$. In Experiments $1 \mathrm{~A}$ and $1 \mathrm{~B}$, an aversion was established to a compound flavor, sucrose-lemon $(\mathrm{AX})$, and generalization of this aversion to a second compound flavor, saline-lemon (BX), was measured. All rats received equivalent prior exposure to all three flavors (A, B, and X), but in different combinations. Group $\mathrm{AX}$ received exposure to the compound $A X$ and to $B$ and $X$ alone, while Group $B X$ received exposure to $\mathrm{BX}$ and to $\mathrm{A}$ and $\mathrm{X}$ alone. The control group (used only in Experiment $1 \mathrm{~A}$ ) received exposure to the three separate flavors (A, B, and X).

According to the associative analysis presented in the introduction, the formation of an association between $\mathrm{A}$ and $X$ when they are presented in compound during preexposure will allow retrieval of A during the test to BX (mediated generalization), whereas the formation of an association between $B$ and $X$ will allow retrieval of $B$ during conditioning trials with $\mathrm{AX}$ (mediated conditioning). Thus if generalization from $\mathrm{AX}$ to $\mathrm{BX}$ is increased by mediated generalization, Group AX, preexposed to AX but not $\mathrm{BX}$, should show the strongest aversion to $\mathrm{BX}$ on test. On the other hand, if generalization is increased by mediated conditioning, Group BX, preexposed to BX but not $\mathrm{AX}$, should show the strongest aversion. The prediction is that generalization from $\mathrm{AX}$ to $\mathrm{BX}$ will be greatest in Group AX. It is possible, of course, that a stronger aversion to BX on test in Group AX might arise from neophobia to the novel $\mathrm{BX}$ compound, but if this is true, the control group, which also never received $\mathrm{BX}$ during preexposure, should show an equally strong aversion on test.

\section{Method}

\section{Animals and Apparatus}

The subjects were 52 male hooded Lister rats (OLAC, Bicester, England), weighing $320-500 \mathrm{~g}$ prior to conditioning; 36 were used in Experiment $1 \mathrm{~A}$ and 16 in Experiment IB. They were housed in groups of 4, under a natural 12:12-h light:dark cycle, and were maintained on a 22.5 -h water-deprivation schedule, with free access to food. The apparatus, housed in a different room, consisted of eight rectangular opaque plastic cages, $30 \times 12.5 \times 11 \mathrm{~cm}$, with wire mesh ceilings and fronts. Fluid was presented through an aperture in the front of each drinking cage in a $50-\mathrm{ml}$ cylinder fitted with a metal spout.

\section{Procedure}

Pretraining. Following initial water deprivation, all animals received 3 days of preliminary training, during which they were placed in the drinking cages with access to water for $10 \mathrm{~min}$. Throughout this phase and for the remainder of the experiment, all rats received two sessions per day. The morning session was run at 11:00 a.m. and the afternoon session at 15:00 p.m.

Preexposure. The design of Experiment 1 is outlined in Table 1. The solutions used were the following: $2 \%$ lemon ( $2 \%$ lemon by volume Sainsbury's Pure Lemon Juice; $X$ ), which served as the common element; $2 \%$ sucrose (A), and $0.9 \%$ saline (B). Following preliminary training, the 36 rats of Experiment $1 \mathrm{~A}$ were randomly divided into three equal groups: AX, BX, and CONT. These animals were run in two identical replications with 8 animals per group in the first replication and 4 animals per group in the second. The 16 rats of Experiment 1B were divided into two equal groups, AX and BX. Over the 24 days ( 48 sessions) of preexposure, the animals in Group AX received 12 presentations of the compound flavor sucrose-lemon and 12 presentations each of the single flavors saline and lemon (AX, B, and X). The animals in Group BX received 12 presentations of saline-lemon and 12 presentations each of sucrose and lemon (BX, A, and X), whereas those in Group CONT (of Experiment $1 \mathrm{~A}$ ) received 12 presentations each of saline and sucrose and 24 presentations of lemon $(A, B$, and $X)$. The solutions were alternated and the order of presentation was arranged so that each solution was given equally often during the morning and afternoon sessions. The animals in Groups AX and BX received water during the sessions when they were not scheduled to receive a flavor. Over the first cycle of 4 days (eight sessions), all the animals were allowed sufficient time to consume a fixed $4 \mathrm{ml}$ of the solution. This amount was increased to $6 \mathrm{ml}$ over the remaining 20 days (40 sessions).

Conditioning. On the morning of Day 25 , following the last preexposure session, all the animals consumed a fixed $8 \mathrm{ml}$ of sucrose-lemon (AX), followed by a $15-\mathrm{ml} / \mathrm{kg}$ intraperitoneal injection of $0.15 \mathrm{M}$ lithium chloride. During the afternoon session, and the following morning session, all the animals received $10 \mathrm{~min}$ of access to water in the drinking cages. They then received a second conditioning trial during the afternoon session of Day 26, during which they received $10 \mathrm{~min}$ of access to sucrose-lemon, followed by a further $15-\mathrm{ml} / \mathrm{kg}$ injection of lithium chloride. In Experiment $1 \mathrm{~B}$, in an attempt to increase the strength of the aversion to 
Experiment 1A

Experiment 1B

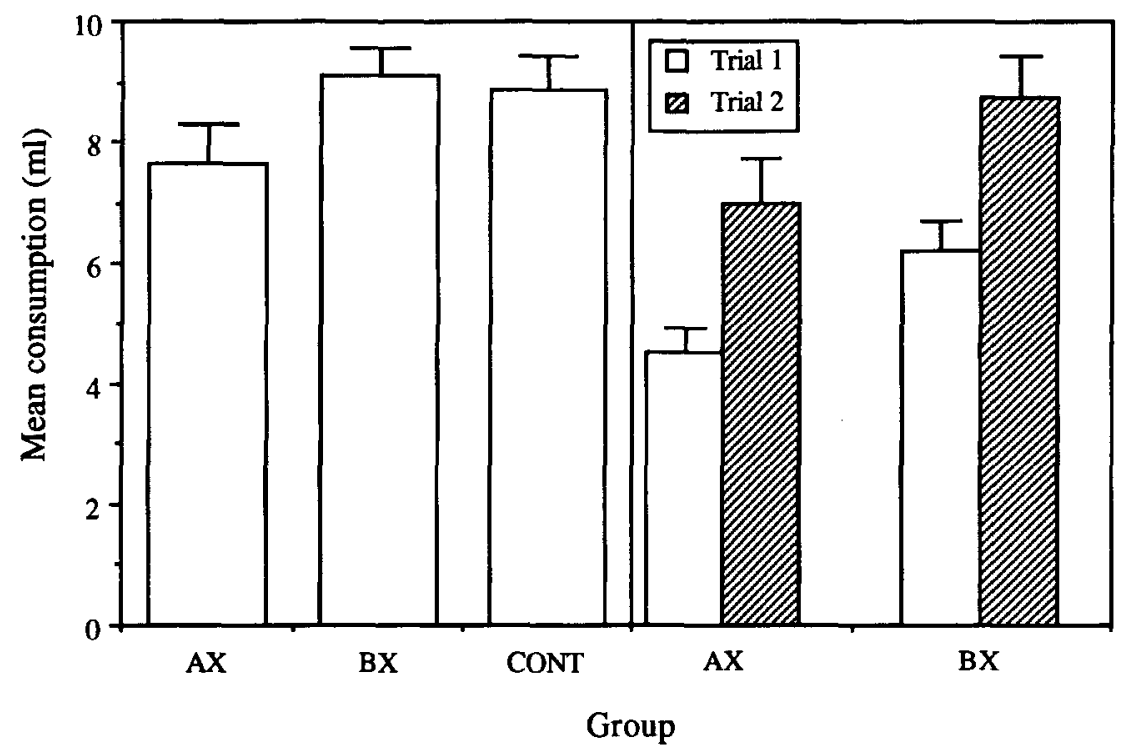

Figure 1. Left panel: Mean test consumption of BX in Groups AX, BX, and CONT of Experiment 1A. Right panel: Mean test consumption of $B X$ in Groups $A X$ and BX of Experiment $1 B$. Error bars illustrate the standard error of the mean.

$\mathrm{AX}$, the animals received a third conditioning trial, during which they received $10 \mathrm{~min}$ of access to sucrose-lemon (AX), followed by a $10-\mathrm{ml} / \mathrm{kg}$ injection of lithium chloride. Unfortunately, because of experimenter error, these animals also received a session during which they were given 10 min of access to $\mathrm{AX}$ which was not followed by an injection of lithium. This session occurred after the first conditioning trial but before the second and third conditioning trials. On the next day, the animals received recovery sessions in the morning and afternoon, during which they received $10 \mathrm{~min}$ of access to water in the drinking cages.

Test. Following the recovery sessions, all the animals received 10 min of access to saline-lemon during the morning session of the following day. The animals in Experiment $1 \mathrm{~B}$ received a second test trial with saline-lemon during the afternoon session.

\section{Results and Discussion}

A significance level of $p<.05$ was adopted throughout the paper.

\section{Conditioning}

On the second conditioning trial to $\mathrm{AX}$, all the animals in Experiment 1A drank more than the fixed $8 \mathrm{ml}$ they had received on the first conditioning trial: Those in Group AX drank $10.44 \mathrm{ml}$, those in Group BX drank $10.81 \mathrm{ml}$, and those in Group CONT drank $10.41 \mathrm{ml}$. An analysis of variance (ANOVA: group $\times$ replication) revealed no differences in consumption between groups $(F<1)$, nor any interaction between this factor and replication $[F(2,30)=1.00]$.

On the second conditioning trial to AX in Experiment $1 \mathrm{~B}$, following fixed consumption on the first trial and $10 \mathrm{~min}$ of free access during a second unreinforced trial, animals in Group AX drank $15.25 \mathrm{ml}$ and those in
Group BX drank $18.00 \mathrm{ml}$. The conditioning procedure was effective, since consumption declined on the third conditioning trial to $2.88 \mathrm{ml}$ in Group AX and $2.50 \mathrm{ml}$ in Group BX. An ANOVA (group $\times$ trial) revealed a main effect of trial $[F(1,14)=311.08]$, but no overall difference in consumption between groups $[F(1,14)=2.12]$. The interaction between group and trial fell short of significance $[F(1,14)=3.91]$, and analysis of simple effects showed that the groups did not differ on the second or third conditioning trials $[F(1,14)=3.04$ and $F<1$, respectively].

\section{Test}

Consumption of $\mathrm{BX}$ during the generalization test is shown in Figure 1. The results of Experiment $1 \mathrm{~A}$ are shown in the left panel and those of Experiment $1 \mathrm{~B}$ in the right panel. In Experiment $1 \mathrm{~A}$, the difference in consumption between groups is numerically quite small, but it appears that animals in Group AX drank less than those in the other two groups. An ANOVA (group $\times$ replication) revealed a difference between groups which fell short of significance $[F(2,30)=2.90]$. However, orthogonal planned contrasts showed that Groups BX and CONT did not differ $(F<1)$, but that these two groups in combination did differ significantly from Group $\mathrm{AX}[F(1,30)=$ $6.40]$. There was also a difference between replications $[F(1,30)=25.81]$; the animals in the first replication drank less than those in the second replication $(7.21 \mathrm{vs} .9 .88 \mathrm{ml})$, but this factor did not interact with group $(F<1)$.

It is clear, from the right-hand panel of Figure 1, that generalization from $\mathrm{AX}$ to $\mathrm{BX}$ in Experiment $1 \mathrm{~B}$ was greater in Group AX than it was in Group BX. An ANOVA 
(group $\times$ trial) confirmed this observation. There was a significant effect of group $[F(1,14)=7.65]$ and of trial $[F(1,14)=26.69]$. The interaction between group and trial was not significant $(F<1)$.

The results of Experiments $1 \mathrm{~A}$ and $1 \mathrm{~B}$ provide support for the notion that the major source of generalization between $\mathrm{AX}$ and $\mathrm{BX}$, over and above that depending on the strength of conditioning to the common X element, is X's retrieval of A during presentation of BX on test. The difference between groups was only moderate in Experiment $1 \mathrm{~A}$, but since animals in the control group drank a similar amount of AX during conditioning as did those in Group BX, and they drank more BX on test than did Group $A X$, it is clear that the pattern of results suggested in Experiment $1 \mathrm{~A}$ and confirmed in Experiment $1 \mathrm{~B}$ cannot be explained in terms of neophobia to novel compound flavors in the two experimental groups. One obvious problem with Experiment 1A, which might account for the relatively small difference between groups in consumption of BX on test, was that the aversion established to $\mathrm{AX}$ was weak and thus generalization to $\mathrm{BX}$ was quite poor. With an increase in the number of conditioning trials to $\mathrm{AX}$ in Experiment 1B, and a consequent increase in generalization to $\mathrm{BX}$, the difference between groups was reliable.

\section{EXPERIMENT 2}

Experiment 2 was designed to test the idea that the inhibitory association crucial for preventing mediated generalization from $\mathrm{AX}$ to $\mathrm{BX}$ should be that from $\mathrm{B}$ to $\mathrm{A}$, rather than that from $A$ to $B$. As in Experiment 1, animals were tested for generalization to saline-lemon $(\mathrm{BX})$ of an aversion established to sucrose-lemon (AX), following different preexposure regimes. Animals in Group AX $\rightarrow$ $B X$, received preexposure trials in which a presentation of sucrose-lemon was always immediately followed by presentation of saline-lemon, whereas those in Group BX $\rightarrow$ $\mathrm{AX}$ received the opposite presentation of solutions: saline-lemon immediately followed by sucrose-lemon. The implication from a number of Pavlovian experiments (e.g., Ewing, Larew, \& Wagner, 1985; Kleiman \& Fowler, 1984; Maier, Rapaport, \& Wheatley, 1976; Wagner \& Brandon, 1989; Wagner \& Larew, 1985) is that this sequential presentation of $\mathrm{AX}$ and $\mathrm{BX}$ might be an especially effective way of establishing a backward inhibitory association between the second flavor and the first. Thus an associative analysis of the two schedules of preexposure would assume that presentations of $A X$ followed by $\mathrm{BX}$ would establish an inhibitory association from $\mathrm{B} \dashv \mathrm{A}$, whereas exposure to $\mathrm{BX}$ followed by $\mathrm{AX}$ would establish an inhibitory $A \dashv B$ association. If, as is suggested by the results of Experiments $1 \mathrm{~A}$ and $1 \mathrm{~B}$, the primary role of inhibitory associations is to prevent mediated generalization to $B X$, via X's retrieval of A on test, then animals exposed to $\mathrm{AX}$ followed by $\mathrm{BX}$ should show less generalization to BX than animals exposed to BX followed by AX. A third group was included as a control: Animals in Group BLK received equivalent exposure to $\mathrm{AX}$ and $\mathrm{BX}$, but in separate blocks of sessions; all presentations of $\mathrm{AX}$ were followed by presentations of $\mathrm{BX}$ (or vice versa).

\section{Method}

\section{Animals and Apparatus}

Forty-eight male hooded Lister rats weighing $310-410 \mathrm{~g}$ prior to conditioning were used. The experiment was run in two replications, $2 \mathrm{~A}$ and $2 \mathrm{~B}$, with 24 rats in each replication. The animals were housed and maintained exactly as in Experiment $1 \mathrm{~A}$.

\section{Procedure}

Pretraining. The design of Experiment 2 is outlined in Table 1. Unless otherwise stated, the procedures were the same as those in Experiment 1 . The rats were randomly divided into three equal groups: $\mathrm{BLK}, \mathrm{AX} \rightarrow \mathrm{BX}$, and $\mathrm{BX} \rightarrow \mathrm{AX}$. After one day of water training as in Experiment 1 , the rats received a further 2 days of training. During each session (morning and afternoon), all the rats were presented with $4 \mathrm{ml}$ of water in one drinking tube and were allowed 2 min to drink it before presentation of a second $4 \mathrm{ml}$ in a second drinking tube. This procedure continued throughout the preexposure phase.

Preexposure. The solutions used were the following: $2 \%$ sucrose (A); $0.9 \%$ saline (B); and either $3 \%$ (Experiment $2 \mathrm{~A}$ ) or $2 \%$ (Experiment 2B) lemon (lemon by volume Sainsbury's Pure Lemon Juice; $X$ ). Over the 12 days ( 24 sessions) of preexposure, rats in Group $\mathrm{AX} \rightarrow \mathrm{BX}$ always received $4 \mathrm{ml}$ of sucrose-lemon followed by $4 \mathrm{ml}$ of saline-lemon, whereas those in Group BX $\rightarrow$ AX always received $4 \mathrm{ml}$ of saline-lemon followed by $4 \mathrm{ml}$ of sucrose-lemon The animals in Group BLK received the same solution in each preexposure session, divided into two presentations of $4 \mathrm{ml}$. Half the animals received sucrose-lemon, morning and afternoon, for the first 6 days of preexposure, and saline--lemon over the second 6 days. The other half received saline-lemon for 6 days followed by 6 days of sucrose-lemon. All the animals were allowed 2 min to drink the first $4 \mathrm{ml}$ of solution before presentation of the second $4 \mathrm{ml}$. Since, after the first session of preexposure, the animals drank the initial $4 \mathrm{ml}$ within $1 \mathrm{~min}$ and it took one or two seconds to remove the first bottle from each cage and replace it with the second, this procedure normally resulted in an interval of at least $1 \mathrm{~min}$ between consumption of the two flavors.

Conditioning and Test. The general conditioning procedure was the same as in Experiment 1 except that the dosage of lithium chloride was $20 \mathrm{ml} / \mathrm{kg}$. In Experiment $2 \mathrm{~A}$, there were two conditioning trials, and in Experiment 2B, there were three. Following two recovery sessions on the day after the final conditioning trial, the animals were tested for consumption of $\mathrm{BX}$ and $\mathrm{X}$ in two 10min sessions.

\section{Results and Discussion}

The data for 1 animal from Group BLK in Experiment $2 \mathrm{~B}$ were excluded from the following analyses, due to spillage of fluid during the second conditioning trial.

\section{Conditioning}

On the second conditioning trial to $\mathrm{AX}$, all animals in Experiment $2 \mathrm{~A}$ drank less than the fixed $8 \mathrm{ml}$ that they had consumed before their first injection: Group BLK, $6.69 \mathrm{ml}$; Group $\mathrm{AX} \rightarrow \mathrm{BX}, 5.34 \mathrm{ml}$; Group BX $\rightarrow \mathrm{AX}$, $5.31 \mathrm{ml}$. There was no difference in consumption between the three groups $[F(2,21)=1.25]$.

On the second conditioning trial to $\mathrm{AX}$ in Experiment 2B, animals in Group BLK drank $9.21 \mathrm{ml}$, those in 


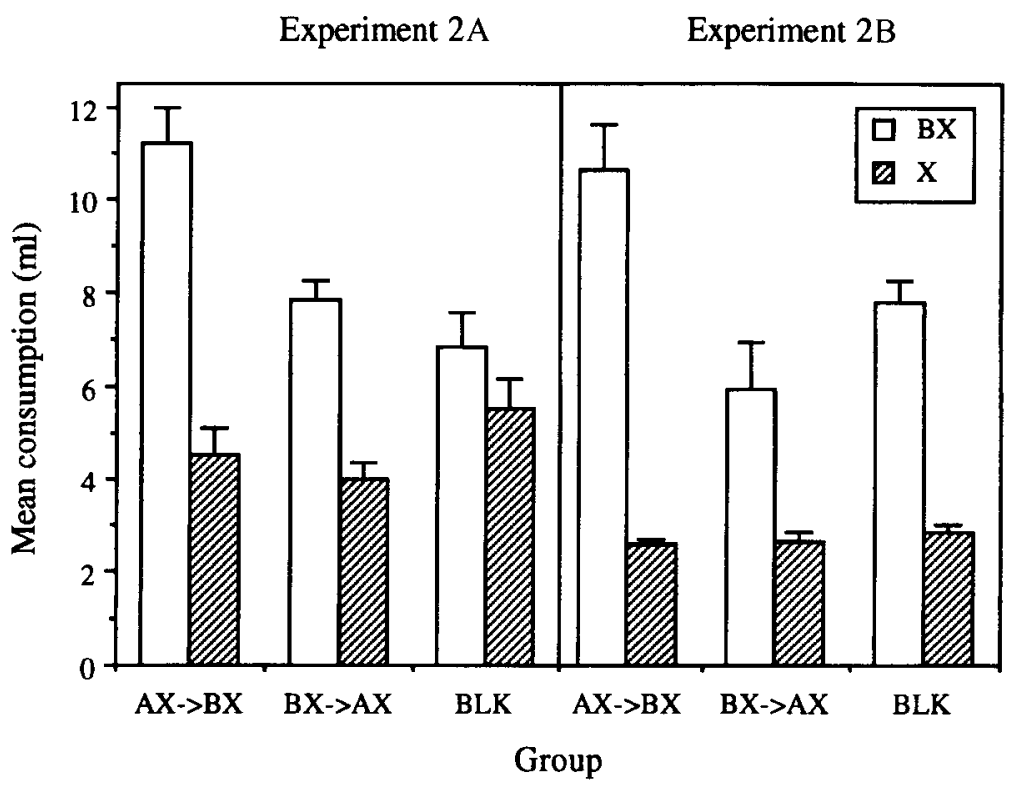

Figure 2. Mean test consumption of $B X$ and $X$ in Groups $A X \rightarrow B X, B X \rightarrow A X$, and BLK. Left panel: Experiment 2A. Right panel: Experiment 2B. Error bars illustrate the standard error of the mean.

Group AX $\rightarrow$ BX drank $7.50 \mathrm{ml}$, and those in Group BX $\rightarrow$ AX drank $9.37 \mathrm{ml}$. Consumption declined on the third trial to $5.00 \mathrm{ml}$ in Group BLK, $2.81 \mathrm{ml}$ in Group $\mathrm{AX} \rightarrow \mathrm{BX}$, and $4.18 \mathrm{ml}$ in Group $\mathrm{BX} \rightarrow \mathrm{AX}$. The decrease in consumption from the second to the third conditioning trial was significant $[F(1,20)=75.77]$, and there was an unexpected, but significant, difference in consumption between the three groups $[F(2,20)=4.83]$, which did not interact with trial $(F<1)$. Newman Keul's pairwise comparisons revealed that the animals in Group $\mathrm{AX} \rightarrow \mathrm{BX}$ drank significantly less AX overall than did those in the other two groups, which did not differ from one another. The reason for this difference is not immediately apparent, since no such difference appeared in Experiment 2A, where Group $\mathrm{AX} \rightarrow \mathrm{BX}$ drank marginally more on the second conditioning trial than did Group $\mathrm{BX} \rightarrow \mathrm{AX}$. However, the difference does not present any problem for the interpretation of the results of the generalization test to BX, since stronger conditioning to $\mathrm{AX}$ should, other things being equal, mean a stronger generalized aversion to $\mathrm{BX}$ in this group, and we are predicting the opposite outcome.

\section{Test}

Consumption of $\mathrm{BX}$ and $\mathrm{X}$ during the two test sessions is shown in Figure 2. The left panel illustrates the results of Experiment $2 \mathrm{~A}$, and the right-hand panel shows the results of Experiment 2B. It is apparent that in both experiments, animals in Group $\mathrm{AX} \rightarrow \mathrm{BX}$ showed less generalization to BX than did those in the other two groups. Separate ANOVAS (group $\times$ trial) revealed a difference between groups in both experiments $[F(2,21)=10.91$, and $F(2,20)=7.40$, respectively], and Newman Keul's pairwise comparisons confirmed that in both experiments
Group $\mathrm{AX} \rightarrow \mathrm{BX}$ drank more BX than did Groups BLK and $\mathrm{BX} \rightarrow \mathrm{AX}$, and that the latter two groups did not differ from one another.

Consumption of $\mathrm{X}$ alone did not differ between groups in either experiment $[F(2,21)=1.98$, and $F<1$, respectively].

In both Experiments $2 \mathrm{~A}$ and $2 \mathrm{~B}$, the animals that received a preexposure regime designed to establish an inhibitory association from $\mathrm{B}$ to $\mathrm{A}$ (Group $\mathrm{AX} \rightarrow \mathrm{BX}$ ) showed less generalization from $\mathrm{AX}$ to $\mathrm{BX}$ than did the animals that received a preexposure regime designed to establish an inhibitory association from $\mathrm{A}$ to $\mathrm{B}$ (Group BX $\rightarrow$ $A X)$. This finding supports the idea that the critical inhibitory association for reducing generalization between $A X$ and $B X$ is $B \dashv A$ rather than $A \dashv B$. Indeed, the animals in Group $B X \rightarrow A X$ showed a level of generalization from AX to BX similar to that for those in Group BLK, where inhibitory associations would be assumed to play little part in reducing generalization between the two.

In neither Experiment 2A nor Experiment 2B did the three groups differ in the strength of conditioning to the common X element, which indicates that the difference in generalization to BX cannot be explained by appealing to differences in the strength of conditioning to the common $\mathrm{X}$ element.

\section{EXPERIMENT 3}

The results of Experiment 2 make it clear that presentation of AX followed by BX on each trial of preexposure is more effective in reducing generalization from $A X$ to $\mathrm{BX}$ than is presentation of $\mathrm{BX}$ followed by AX. Our assumption is that this is because the backward pairing of 
$\mathrm{BX}$ and $\mathrm{AX}$ in Group $\mathrm{AX} \rightarrow \mathrm{BX}$ results in a stronger inhibitory association from $\mathrm{B}$ to $\mathrm{A}$ than does the forward pairing that occurs in Group $\mathrm{BX} \rightarrow \mathrm{AX}$, and that it is the inhibition of A by B on BX test trials that is most important in reducing mediated generalization from $\mathrm{AX}$ to $\mathrm{BX}$. But our argument would be greatly strengthened by independent, and more direct, evidence of differences in the structure of inhibitory associations formed between $\mathrm{A}$ and $B$ as a result of these different schedules of preexposure.

A rather striking set of results reported by Espinet, Iraola, Bennett, and Mackintosh (1995) suggests a procedure for generating the independent evidence that we need. In those experiments, rats received alternating exposure to two compound flavors, $\mathrm{AX}$ and $\mathrm{BX}$, and if an aversion was subsequently established to $A$ alone through the pairing of its consumption with lithium, B became a conditioned inhibitor as measured by both retardation and summation tests. In two experiments, for example, animals that received such preexposure to $\mathrm{AX}$ and $\mathrm{BX}$ acquired an aversion to $B$ more slowly than various control groups, and in two others, B acted to increase consumption of another flavor independently paired with lithium.

In Experiment 3, therefore, we sought both to replicate some of the results of Espinet et al. (1995) and to compare the magnitude of the inhibition apparently conditioned to $\mathrm{B}$ as a result of prior excitatory conditioning to $\mathrm{A}$ in groups given different schedules of preexposure. All the rats received exposure to two compound flavors, sucrose-lemon $(\mathrm{AX})$ and saline - lemon (BX), before establishing an aversion to $A$ alone and testing the inhibitory properties of $B$ in subsequent retardation (Experiments $3 \mathrm{~A}$ and $3 \mathrm{~B}$ ) and summation tests (Experiment $3 C$ ). Groups $A X \rightarrow B X$ and $B X \rightarrow A X$ received the same schedule of preexposure as did the comparably named groups in Experiment 2: either $\mathrm{AX}$ followed by $\mathrm{BX}$ or $\mathrm{BX}$ followed by $\mathrm{AX}$ within each session of preexposure. Any differences between these two groups in the inhibitory properties of B for the US should provide independent evidence for the structure of the inhibitory associations established during these schedules of preexposure. In Experiments 3A and 3B, Group BLK received all presentations of $A X$ prior to all presentations of BX (or vice versa). In addition, Experiment $3 \mathrm{~A}$ included a fourth group, Group ALT, which received alternating exposure to $\mathrm{AX}$ and $\mathrm{BX}$ in different sessions of preexposure. They were included in order to establish that alternating and blocked preexposure did differ in the extent to which conditioning to A endowed B with inhibitory properties.

\section{Method}

\section{Animals and Apparatus}

The animals were 80 male hooded Lister rats weighing 400 $600 \mathrm{~g}$ prior to conditioning, housed and maintained exactly as in previous experiments; 32 rats were used in Experiment $3 \mathrm{~A}$ and 24 in both Experiments $3 \mathrm{~B}$ and $3 \mathrm{C}$.

\section{Procedure}

Pretraining and preexposure. The design of Experiment 3 is outlined in Table 1. Unless otherwise stated, the procedures were the same as in Experiment 2. Following preliminary training, the rats were randomly divided into four groups of 8 (BLK, ALT, $\mathrm{AX} \rightarrow \mathrm{BX}$ and $\mathrm{BX} \rightarrow \mathrm{AX}$ ) for Experiment $3 \mathrm{~A}$, three groups of 8 (BLK, $\mathrm{AX} \rightarrow \mathrm{BX}, \mathrm{BX} \rightarrow \mathrm{AX}$ ) for Experiment $3 \mathrm{~B}$, and two groups of $12(\mathrm{AX} \rightarrow \mathrm{BX}$ and $\mathrm{BX} \rightarrow \mathrm{AX})$ for Experiment $3 \mathrm{C}$. In Experiment $3 \mathrm{C}$, the animals received two preexposure sessions per day for 12 days, but in Experiments $3 \mathrm{~A}$ and $3 \mathrm{~B}$, the animals received only one session per day, for 24 days, and the amount each drinking tube contained was $6 \mathrm{ml}$ rather than $4 \mathrm{ml}$. The animals in Group ALT of Experiment $3 A$ received preexposure to sucrose-lemon $(A X)$ and saline-lemon (BX) during separate alternating sessions: AX on even days and $\mathrm{BX}$ on odd days. The fourth flavor used as the second excitor in Experiment $3 \mathrm{C}$ was $0.00005 \mathrm{M}$ quinine.

Conditioning to $\mathbf{A}$. Following the final session of preexposure, all the animals received their first conditioning trial, during which they consumed $8 \mathrm{ml}$ of sucrose (A), followed by a $20-\mathrm{ml} / \mathrm{kg}$ injection of lithium chloride in Experiments $3 \mathrm{~A}$ and $3 \mathrm{C}$ and a $15-\mathrm{ml} / \mathrm{kg}$ injection in Experiment 3B. Over the next 2 days, the animals in Experiments $3 \mathrm{~A}$ and $3 \mathrm{~B}$ recsived two more conditioning trials, during which they received 10 min of access to sucrose followed by either $20-\mathrm{ml} / \mathrm{kg}$ injections of lithium chloride in Experiment $3 \mathrm{~A}$ or $10-\mathrm{ml} / \mathrm{kg}$ injections in Experiment $3 \mathrm{~b}$. The animals in Experiment $3 \mathrm{C}$ received one more conditioning trial followed by a 20 $\mathrm{ml} / \mathrm{kg}$ injection of lithium. In Experiments $3 \mathrm{~A}$ and $3 \mathrm{~B}$, recovery sessions were given over the 4 days following the last conditioning trial. The animals in Experiment $3 \mathrm{~A}$ received $10 \mathrm{~min}$ of access to water in the drinking cages during these sessions, whereas those in Experiment $3 \mathrm{~B}$ received $20 \mathrm{~min}$ of access to water. The animals in Experiment $3 \mathrm{C}$ received 2 days of recovery, during which they were given $10 \mathrm{~min}$ of access to water.

Conditioning to quinine. Following recovery, the animals in Experiment $3 \mathrm{C}$ received two conditioning trials to quinine (Q), during which they received $10 \mathrm{~min}$ of access followed by $10-\mathrm{ml} / \mathrm{kg}$ injections of lithium chloride.

Retardation and extinction. In Experiments $3 \mathrm{~A}$ and $3 \mathrm{~B}$, the animals then received two retardation trials, during which they received $10 \mathrm{~min}$ of access to saline (B), followed by a $5-\mathrm{ml} / \mathrm{kg}$ injection of lithium chloride. Since conditioning proceeded very rapidly, the retardation trials were followed by four (Experiment $3 \mathrm{~A}$ ) or six (Experiment 3B) extinction trials, during which the animals received 10 min of access to saline.

Summation. In Experiment 3C, the animals received 2 days of summation testing (AM and PM), during which they were given 10 min of access to quinine (Q) or to saline-quinine (BQ), in the following order: $\mathrm{Q}, \mathrm{BQ}, \mathrm{BQ}, \mathrm{Q}$.

\section{Results and Discussion}

The data from 3 animals from Experiment $3 \mathrm{~A}$ (one from each of Groups BLK, ALT, and AX $\rightarrow B X$ ) were excluded from the following analyses because of spillage of fluid or blocked drinking spouts during critical conditioning or test sessions. In addition, 1 animal from Group $A X \rightarrow$ $\mathrm{BX}$ of Experiment $3 \mathrm{~B}$ became ill during the course of the experiment and its data were excluded from the following analyses. The data for 1 animal from Group BX $\rightarrow$ AX of Experiment $3 \mathrm{~B}$ were also excluded, because of a failure to establish a significant aversion to $\mathrm{A}$.

\section{Conditioning to $\mathbf{A}$}

In Experiment $3 \mathrm{~A}$, on the second conditioning trial to $A$, all animals drank more than the fixed $8 \mathrm{ml}$ given on the first trial: Group BLK drank $10.21 \mathrm{ml}$, Group ALT drank $15.36 \mathrm{ml}$, Group $\mathrm{AX} \rightarrow \mathrm{BX}$ drank $12.00 \mathrm{ml}$, and Group BX $\rightarrow \mathrm{AX}$ drank $16.25 \mathrm{ml}$. The conditioning pro- 


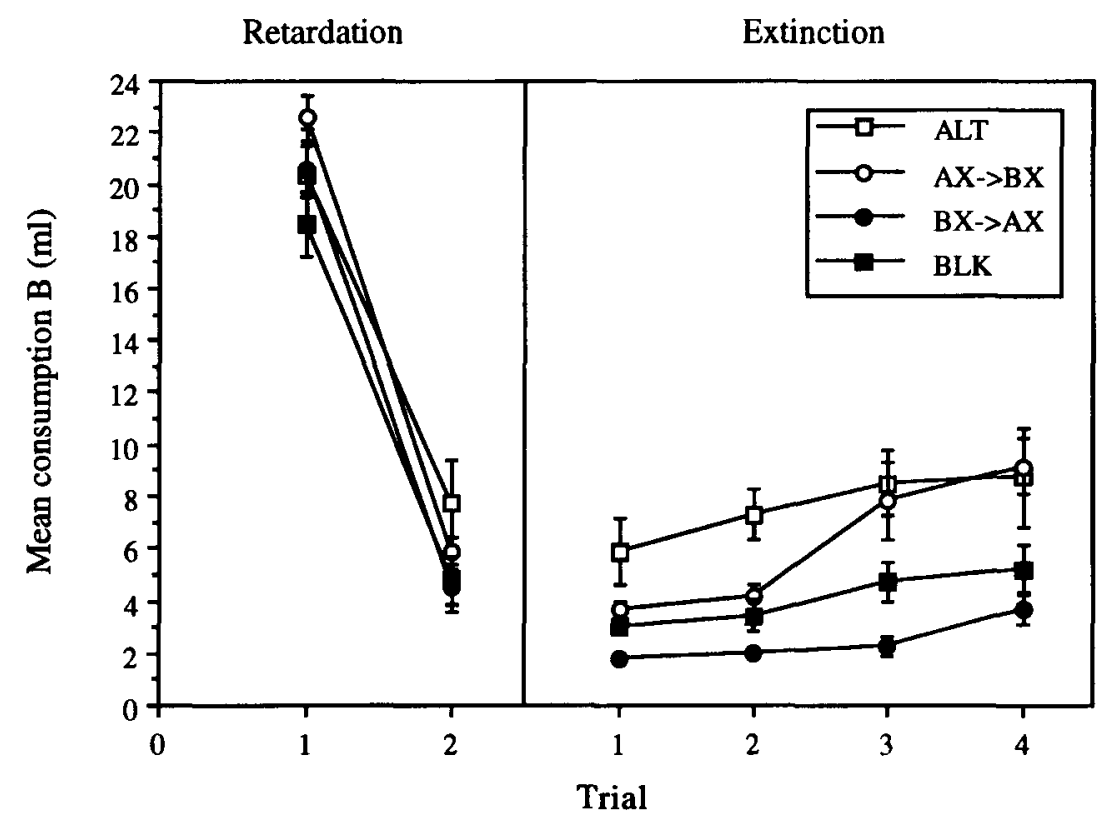

Figure 3. Mean test consumption of B in Groups ALT, $\mathbf{A X} \rightarrow \mathbf{B X}, \mathbf{B X} \rightarrow \mathbf{A X}$, and BLK of Experiment 3A. Left panel: Retardation trials. Right panel: Extinction trials. Error bars illustrate the standard error of the mean.

cedure was effective, since consumption declined on the third trial to $3.57 \mathrm{ml}$ in Group BLK, $6.86 \mathrm{ml}$ in Group ALT, $2.43 \mathrm{ml}$ in Group $\mathrm{AX} \rightarrow \mathrm{BX}$, and $3.00 \mathrm{ml}$ in Group BX $\rightarrow$ $\mathrm{AX}$. The decrease in consumption from the second to the third conditioning trial was significant $[F(1,25)=193.68]$, as was the difference in consumption between groups $[F(3,25)=4.33]$, and Newman Keul's pairwise comparisons showed that animals in Group ALT drank more overall than those in Groups BLK and $\mathrm{AX} \rightarrow \mathrm{BX}$, which did not differ from one another. Overall consumption in Group $\mathrm{BX} \rightarrow \mathrm{AX}$ did not differ from that in any other group. The interaction between group and trial was also significant $[F(3,25)=4.16]$, and analysis of simple effects showed that the difference between groups was significant on both trials [smallest $F(3,25)=3.72$ ], and that the decrease in consumption of A from the second to the third conditioning trial was significant for all groups [smallest $F(1,25)=22.98]$.

The comparable data for Experiment $3 \mathrm{~B}$ were as follows: On the second conditioning trial to $A$, the animals in Group BLK drank $15.44 \mathrm{ml}$, those in Group $\mathrm{AX} \rightarrow \mathrm{BX}$ drank $15.07 \mathrm{ml}$, and those in Group $\mathrm{BX} \rightarrow \mathrm{AX}$ drank $12.93 \mathrm{ml}$. Consumption declined on the third trial to $6.94 \mathrm{ml}$ in Group BLK, $5.43 \mathrm{ml}$ in Group $\mathrm{AX} \rightarrow \mathrm{BX}$, and $6.29 \mathrm{ml}$ in Group $B X \rightarrow A X$. There was a main effect of trial $[F(1,19)=128.27]$, but the difference in consumption between groups fell short of significance $[F(2,19)=2.77]$, and the interaction between groups and trials was not significant $(F<1)$.

On the second conditioning trial to $\mathrm{A}$, the animals in Group $\mathrm{AX} \rightarrow \mathrm{BX}$ of Experiment $3 \mathrm{C}$ drank $10.71 \mathrm{ml}$ and those in Group BX $\rightarrow \mathrm{AX}$ drank $9.46 \mathrm{ml}$. There was no difference in consumption between groups $[F(1,22)=1.13]$.

\section{Conditioning to $Q$}

During conditioning to the second excitor in Experiment 3C, the animals in Group $\mathrm{AX} \rightarrow \mathrm{BX}$ drank $6.29 \mathrm{ml}$ during the first trial and $2.96 \mathrm{ml}$ during the second. Group BX $\rightarrow$ AX drank $5.75 \mathrm{ml}$ and $3.33 \mathrm{ml}$, respectively. There was a main effect of trial $[F(1,22)=119.30]$, but no difference in consumption between groups $(F<1)$, and the interaction between groups and trials was not significant $[F(1,22)=3.03]$.

\section{Experiments 3A and 3B: \\ Retardation and Extinction Tests}

Mean consumption of $B$ over the two retardation trials of Experiment $3 \mathrm{~A}$ is shown in the left-hand panel of Figure 3. It is apparent that the acquisition of an aversion to B was extremely rapid and substantial in all groups, and there seems to be little difference between them. An ANOVA (group $\times$ trial) confirmed that there were no differences between groups $[F(3,25)=1.40]$ but that the overall decrease in consumption of $B$ from the first to the second retardation trial was significant $[F(1,25)=$ $691.02]$. The interaction between groups and trials was also significant $[F(3,25)=3.10]$, but analysis of simple effects revealed that there were no differences between groups on either trial $[F(3,25)=1.77$ and 1.78 , respectively], and that the decrease in consumption of B was significant for all groups [smallest $F(1,25)=121.57$ ]

The comparable data for Experiment 3B are shown in the left-hand panel of Figure 4. It is apparent that animals in Group $\mathrm{AX} \rightarrow \mathrm{BX}$ showed a weaker aversion to $\mathrm{B}$ than did those in Groups BX $\rightarrow A X$ and BLK. An ANOVA confirmed this observation; there was a significant difference between groups $[F(2,19)=8.03]$, and Newman Keul's 


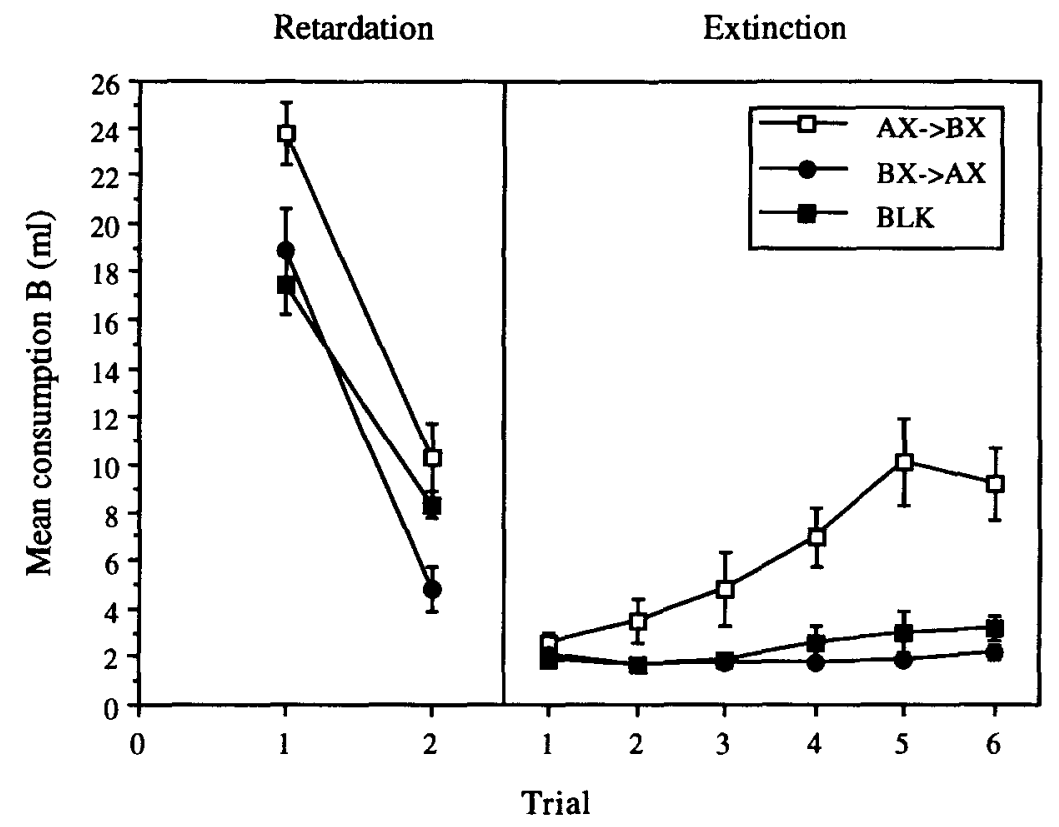

Figure 4. Mean test consumption of $B$ in Groups $A X \rightarrow B X, B X \rightarrow A X$, and $B L K$ of Experiment 3B. Left panel: Retardation trials. Right panel: Extinction trials. Error bars illustrate the standard error of the mean.

pairwise comparisons revealed that Group $\mathrm{AX} \rightarrow \mathrm{BX}$ drank more than Groups BX $\rightarrow$ AX and BLK, which did not differ from one another. The aversion established to $B$ increased substantially from the first to the second trial $[F(1,19)=280.71]$. The interaction between group and trial was not significant $[F(2,19)=1.43]$.

Mean consumption of $\mathrm{B}$ over the four extinction trials of Experiment $3 \mathrm{~A}$ is shown in the right-hand panel of Figure 3. It is clear that extinction of the aversion to $B$ was faster in Groups ALT and $A X \rightarrow B X$ than it was in the other two groups. An ANOVA (group $\times$ trial) revealed that the overall difference between groups was significant $[F(3,25)=8.15]$. There was also a main effect of trial $[F(3,75)=30.60]$, and a significant interaction between group and trial $[F(9,75)=3.35]$. Since the interaction was reliable and since analysis of simple effects showed that the difference between groups was significant on all four trials [smallest $F(3,25)=4.99$ ], separate ANOVAS were conducted on the data from each extinction trial. Newman Keul's pairwise comparisons showed that on the first and second extinction trials, animals in Group ALT drank more $B$ than did those in the other three groups, which did not differ from one another. On the third trial, Groups ALT and $\mathrm{AX} \rightarrow \mathrm{BX}$ drank more than Groups BLK and BX $\rightarrow \mathrm{AX}$, and these two pairs of groups did not differ from one another. On the final trial, Groups ALT and AX $\rightarrow B X$ drank more than Group BX.

Mean consumption of $\mathrm{B}$ over the six extinction trials of Experiment 3B is shown in the right-hand panel of Figure 4 . These results mirror those from the retardation trials; extinction of the aversion to $\mathrm{B}$ was faster in Group $\mathrm{AX} \rightarrow \mathrm{BX}$ than in the other two groups. Indeed, the animals in Groups BX $\rightarrow$ AX and BLK showed little increase in their consumption of $B$ over the six trials. An ANOVA (group $\times$ trial) revealed that the difference between groups was significant $[F(2,19)=11.96]$, and Newman Keul's pairwise comparisons showed that Group $\mathrm{AX} \rightarrow \mathrm{BX}$ drank more than Groups $\mathrm{BX} \rightarrow \mathrm{AX}$ and $B L K$, which did not differ from one another. There was a main effect of trial $[F(5,95)=19.71]$, and a significant interaction between group and trial $[F(10,95)=10.90]$. Analysis of simple effects showed that the difference between groups was significant on all but the first extinction trial [smallest $F(2,19)=4.27$ ], and that the increase in consumption of $B$ over trials was significant only for Group $\mathrm{AX} \rightarrow \mathrm{BX}[F(5,95)=37.93 ; F(5,95)=1.91$ and $F<1$ for Groups BLK and $\mathrm{BX} \rightarrow \mathrm{AX}$, respectively].

\section{Experiment 3C: Summation Test}

The results of the summation test of Experiment 3C are shown in Figure 5. The figure suggests that while animals in Groups $\mathrm{AX} \rightarrow \mathrm{BX}$ and $\mathrm{BX} \rightarrow \mathrm{AX}$ drank similar amounts of $Q$ alone, those in Group $A X \rightarrow B X$ drank more of the BQ compound than did those in Group BX $\rightarrow$ AX. An ANOVA conducted on the data for consumption of $Q$ alone revealed an increase in consumption from the first to the second trial which fell short of significance $[F(1,22)=4.12]$, but no other differences were significant $(F \mathrm{~s}<1)$. The critical analysis was performed on difference scores: consumption of the $\mathrm{BQ}$ compound minus consumption of $Q$ alone. This revealed a significant difference between groups $[F(1,22)=9.16]$ and a main effect of trial $[F(1,22)=61.92]$. The interaction between groups and trials was not significant $[F(1,22)=1.48]$. 


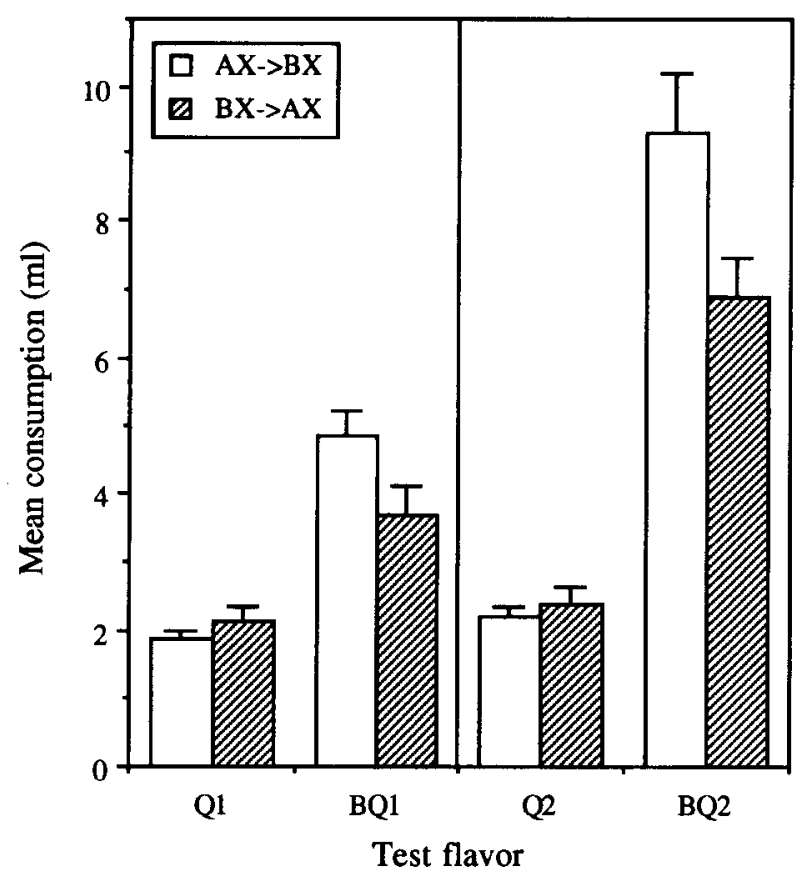

Figure 5. Mean test consumption of quinine (Q) and saline-quinine (BQ) flavors in Groups $A X \rightarrow B X$ and $B X \rightarrow A X$ of Experiment 3C. Error bars illustrate the standard error of the mean.

Although there were no differences in the inhibitory properties of $\mathrm{B}$ as measured by acquisition of an aversion to $\mathrm{B}$ during the retardation trials of Experiment $3 \mathrm{~A}$, there were clear differences between groups in the extinction of this aversion. Group ALT showed faster extinction of the aversion to B than did any other group, and Group $\mathrm{AX} \rightarrow \mathrm{BX}$ also showed faster extinction than did Groups BLK and BX $\rightarrow \mathrm{AX}$.

This pattern of results is consistent with the argument that alternating exposure to $\mathrm{AX}$ and $\mathrm{BX}$ is more effective than blocked exposure in establishing inhibitory associations between $\mathrm{A}$ and $\mathrm{B}$, and that the inhibitory association that is responsible for turning $B$ into a conditioned inhibitor of lithium following excitatory conditioning to $\mathrm{A}$ is that from B to A. There are, however, two possible problems with these results. The first is that conditioning to $B$ was so rapid in all groups that it was not possible to see any evidence of inhibition to B during the retardation test: Differences appeared only in extinction. The second is that there were, for no obvious reason, significant differences between the four groups in their rate of conditioning to A, the most notable being the slower conditioning in Group ALT. It might be argued that the reason why Group ALT showed weaker extinction to B during the extinction test was simply that they had also shown weaker conditioning to A. But that is not, in fact, a particularly plausible suggestion. Espinet et al. (1995) showed that evidence of retardation to $B$ precisely depended on excitatory conditioning to $\mathrm{A}$ : The implication, therefore, is that weak excitatory conditioning to $\mathrm{A}$ would have resulted in stronger conditioning to $\mathrm{B}$. Indeed, the other group to show weaker conditioning to $\mathrm{A}$, Group $\mathrm{BX} \rightarrow \mathrm{AX}$, did in fact show stronger excitatory conditioning to $\mathrm{B}$.

The results of Experiment $3 \mathrm{~B}$ confirm the extinction results of Experiment $3 \mathrm{~A}$ : Group $\mathrm{AX} \rightarrow \mathrm{BX}$ showed faster extinction of the aversion to $B$ than did Groups BLK and $\mathrm{BX} \rightarrow \mathrm{AX}$. More important, the effect was evident in the retardation phase: Group $\mathrm{AX} \rightarrow \mathrm{BX}$ was slower to acquire an aversion to $B$ than the other two groups.

The summation results of Experiment $3 \mathrm{C}$ complement the retardation and extinction results of Groups $A X \rightarrow B X$ and $\mathrm{BX} \rightarrow \mathrm{AX}$ in Experiments $\mathrm{A}$ and $3 \mathrm{~B}$. It is clear that $\mathrm{B}$ acted as a stronger conditioned inhibitor in Group $A X \rightarrow$ $\mathrm{BX}$ than in Group BX $\rightarrow \mathrm{AX}$.

It is worth commenting on two aspects of these experiments. First, A and B were always sucrose and saline, respectively, but this lack of counterbalancing does not seem problematic, since previous work (see Espinet et al., 1995, Experiment 4) has provided evidence for inhibition when A and B were either sucrose or saline. Second, there were some procedural differences between the three experiments reported here-most notably the two preexposure sessions per day in Experiment $3 \mathrm{C}$ versus one per day in Experiments $3 \mathrm{~A}$ and $3 \mathrm{~B}$. While the most convincing demonstration of B's inhibitory properties would have been to show retardation and summation effects within the same experiment, or in experiments with identical procedures, it is difficult to see how the effects shown here might have depended on the procedural differences between them.

The results of Experiment $3 \mathrm{~A}$ suggest, first, that the reason why alternating preexposure is more effective than blocked preexposure in reducing generalization from $\mathrm{AX}$ to $\mathrm{BX}$ is that it allows the formation of inhibitory associations between $A$ and $B$, and the results of Experiments $3 \mathrm{~B}$ and $3 \mathrm{C}$ suggest, second, that the more important inhibitory association is that from $\mathrm{B}$ to $\mathrm{A}$.

\section{GENERAL DISCUSSION}

The question that we set out to answer was as follows: Why does alternating preexposure to two flavors, $A X$ and $\mathrm{BX}$, result in less generalization to BX of an aversion conditioning to AX than does the same total amount of exposure to the two compounds, but with all trials to $\mathrm{AX}$ preceding those to BX (or vice versa). Our experiments suggest the following answers.

Exposure to AX and BX will, among other things, result in the formation of excitatory associations between $A$ and $X$ and between $B$ and $X$. These associations might increase generalization from $\mathrm{AX}$ to $\mathrm{BX}$ in one or the other (or both) of two ways. On conditioning trials to AX, $\mathrm{X}$ might retrieve a representation of $\mathrm{B}$ which could then become associated with the US paired with AX. Alternatively, on test trials to $\mathrm{BX}, \mathrm{X}$ might retrieve a representation of $A$ which could in turn elicit the $C R$ conditioned to $A$. The first possibility suggests that it is the association between $\mathrm{B}$ and $\mathrm{X}$ that increases generalization between 
$\mathrm{AX}$ and $\mathrm{BX}$; the second, that it is the association between $A$ and $X$. The results of Experiment 1 suggested that prior establishment of an association between $\mathrm{A}$ and $\mathrm{X}$ was more effective than the establishment of an association between $\mathrm{B}$ and $\mathrm{X}$ in increasing generalization from $\mathrm{AX}$ to $\mathrm{BX}$.

According to McLaren et al. (1989), the reason why alternating exposure to $\mathrm{AX}$ and $\mathrm{BX}$ reduces generalization from $\mathrm{AX}$ to $\mathrm{BX}$ is that any excitatory associations between $A$ and $X$ and between $B$ and $X$ are counteracted by the development of inhibitory associations between $A$ and $B$. Since Experiment 1 suggested that the more important excitatory association was that between $\mathrm{A}$ and $\mathrm{X}$, it follows from McLaren et al.'s analysis that the more important inhibitory association should be that from $B$ to $\mathrm{A}$-allowing the presence of $\mathrm{B}$ on BX test trials to inhibit the retrieval of $A$ and its associated CR by X. The results of Experiment 2 were consistent with this analysis. Presentation of AX followed by $\mathrm{BX}$ on each preexposure trial was more effective than presentation of $\mathrm{BX}$ followed by $\mathrm{AX}$ in reducing generalization from $\mathrm{AX}$ to $\mathrm{BX}$. And presentation of $\mathrm{BX}$ after $\mathrm{AX}$ should have been more effective than presentation of $\mathrm{BX}$ before $\mathrm{AX}$ in establishing an inhibitory association from $\mathrm{B}$ to $\mathrm{A}$.

In Experiment 3, we compared the effect of different schedules of preexposure to $\mathrm{AX}$ and $\mathrm{BX}$ on more direct measures of inhibition between $A$ and $B$. In a series of experiments, Espinet et al. (1995) showed that alternating exposure to two flavors, $\mathrm{AX}$ and $\mathrm{BX}$, followed by the conditioning of an aversion to $A$ alone, was sufficient to turn $B$ into a conditioned inhibitor of the aversive US, as measured by both retardation and summation tests. The results of Experiment 3 confirmed, first, that alternating exposure to $\mathrm{AX}$ and $\mathrm{BX}$ was more effective than blocked exposure in endowing $B$ with inhibitory properties, as measured by the extinction phase of a retardation test; and second, that exposure to $\mathrm{AX}$ followed by $\mathrm{BX}$ in each preexposure session was more effective than exposure to $\mathrm{BX}$ followed by $\mathrm{AX}$ in producing this effect in both retardation and summation tests.

Symonds and Hall (1995), who first showed that alternating preexposure to $\mathrm{AX}$ and $\mathrm{BX}$ was more effective than blocked preexposure in reducing generalization between the two, appealed to a process of comparison or contrast suggested by Gibson (1969) to explain their results. Alternating preexposure, they suggested, increased the opportunity to compare the two stimuli, drawing attention to their unique features, $\mathrm{A}$ and $\mathrm{B}$, rather than to those they shared in common. Bennett and Mackintosh (in press), however, found no evidence that such a process contributed to the reduction in generalization resulting from alternating preexposure to $\mathrm{AX}$ and $\mathrm{BX}$. On the contrary, they identified one mechanism of contrast (short-term habituation to the common $\mathrm{X}$ element) that contributed to an increase in generalization between $\mathrm{AX}$ and $\mathrm{BX}$. The results of the present set of experiments, we should argue, point strongly to a different explanation: that alternating preexposure is more effective than blocked preexposure in establishing inhibitory associations between the unique A and B features. Are there any other explanations of our results? One possibility may be suggested by a modification to SOP (Wagner, 1981) recently proposed by Dickinson and Burke (1996; see also Van Hamme \& Wasserman, 1994). According to Dickinson and Burke, excitatory associations may be formed between a CS and US not only when they are both present (both in the Al state in Wagner's terminology), but also when both are retrieved into memory by the presentation of stimuli previously associated with them (both in Wagner's A2 state). Similarly, an inhibitory association may be established between a CS and US not only when the CS is in A1 and the US in A2 (as Wagner proposed), but also when the CS is in $\mathrm{A} 2$ and the US in A1. This last possibility may seem to suggest an explanation for some of our results. If the representation of $B$ were retrieved into $A 2$ on a conditioning trial to $A X$ (or A), then B in A2 would be paired with the lithium US in A1, and that would establish B as an inhibitor of the US. One would thus expect to see little or no suppression of drinking to BX (in Experiments 1 and 2) and the direct evidence of inhibition to B in Experiment 3.

Yet although this suggestion might in principle explain one or two aspects of our results, there are many more that it wholly fails to address. Consider Experiment 3 (see also Espinet et al., 1995), where the critical operation that produces evidence of inhibition to $B$ is the pairing of $A$ with lithium. Why should $A$ have retrieved a representation of $\mathrm{B}$ into $\mathrm{A} 2$ ? It is conceivable that it might have done so in Group $\mathrm{AX} \rightarrow \mathrm{BX}$, since they were exposed to repeated sequential presentations of $A$ and $B$. This could explain why Group $\mathrm{AX} \rightarrow \mathrm{BX}$ showed more evidence of inhibition to $\mathrm{B}$ than did other groups, but not the pattern of differences between these remaining groups. In other words, there is no explanation of the basic difference between Groups ALT and BLK (Experiment $3 \mathrm{~A}$ ). For all the remaining groups in Experiment 3, the only stimulus that would have retrieved $\mathrm{B}$ into $\mathrm{A} 2$ on a conditioning trial would have been $\mathrm{X}$, but Espinet et al. showed conclusively that conditioning to A, not to $\mathrm{X}$, produced evidence of inhibition to $\mathrm{B}$.

In Experiment 2, conditioning was to $\mathrm{AX}$, so all the animals might have retrieved $B$ into $A 2$ on these conditioning trials. Once again, one might be able to argue that an additional excitatory association between $\mathrm{A}$ and $\mathrm{B}$ in Group $\mathrm{AX} \rightarrow \mathrm{BX}$ would have increased this effect and thus would explain why this group showed little aversion to BX, but once again there would be no explanation of the basic difference between alternating and blocked preexposure conditions. A similarly partial explanation can be provided of the results of Experiment 1 . Here the only group that could have retrieved $\mathrm{B}$ into $\mathrm{A} 2$ on the conditioning trial to $\mathrm{AX}$ was Group $\mathrm{BX}$, and this would certainly explain why this group showed less aversion to $\mathrm{BX}$ than did Group AX. But they should equally have shown less aversion than the control group, and in Experiment 1 A, there was no suggestion of such a pattern of results.

It is worth adding that there is actually no direct evidence that pairing a CS in A2 with a US such as lithium, 
shock, or food in Al establishes inhibitory conditioning to that CS. On the contrary, the only effect observed in standard animal conditioning experiments employing such USs is that it may produce weak excitatory conditioning to the CS (Holland, 1981; Ward-Robinson \& Hall, 1996).

A second possible explanation of some of the differences between Groups $\mathrm{AX} \rightarrow \mathrm{BX}$ and $\mathrm{BX} \rightarrow \mathrm{AX}$ in Experiments 2 and 3 is that their preexposure might have resulted in differences in the amount of latent inhibition accruing to BX (or B). According to Lubow, Weiner, and Schnur (1981), latent inhibition is disrupted if the target stimulus is always followed by another during preexposure. Thus latent inhibition to BX might have proceeded normally in Group $\mathrm{AX} \rightarrow \mathrm{BX}$, where $\mathrm{BX}$ was followed by nothing, but been disrupted in Group $\mathrm{BX} \rightarrow \mathrm{AX}$, where it was always followed by AX. Since there is evidence that preexposure to $\mathrm{BX}$ alone will reduce the generalization to BX of an aversion conditioned to AX (e.g., Bennett et al., 1994), a difference in latent inhibition to BX might in principle account for the difference in test performance between Groups $\mathrm{AX} \rightarrow \mathrm{BX}$ and $\mathrm{BX} \rightarrow \mathrm{AX}$ in Experiment 2 . And it might equally account for the difference between these two groups in the retardation and extinction tests of Experiments $3 \mathrm{~A}$ and $3 \mathrm{~B}$. But there are many more aspects of our results that such an account fails to explain. It fails to explain the difference between these two groups in the summation test of Experiment $3 \mathrm{C}$. It predicts that Group BX $\rightarrow$ AX should have shown more generalization to BX than Group BLK showed in Experiment 2, and faster conditioning to B than Group BLK showed in Experiment 3. Like the Dickinson and Burke (1996) modification to SOP, it equally fails to account for the basic difference between alternating and blocked schedules of preexposure that we are setting out to explain. And it also rests on some distinctly insecure foundations. Hall (1991) reviews a number of experiments that have failed to yield any disruption of latent inhibition when a target stimulus was followed by another during preexposure. And where such an effect has occurred, there has been rather good evidence that it was simply due to generalization decrement between preexposure to two sequential stimuli and conditioning to only one. Preexposure to BX preceded by AX (in Group $\mathrm{AX} \rightarrow \mathrm{BX}$ ) would surely have resulted in as much generalization decrement as did preexposure to BX followed by AX (Group BX $\rightarrow$ AX). Finally, Bennett et al. (1994) showed that the reason why preexposure to $\mathrm{BX}$ reduced generalization between $\mathrm{AX}$ and $\mathrm{BX}$ was simply that such preexposure generated latent inhibition to $\mathrm{X}$, thus ensuring that when AX was paired with a US, conditioning accrued to $A$ rather than to $X$. Latent inhibition of X, of course, would have been as much (or as little) disrupted in Group $\mathrm{AX} \rightarrow \mathrm{BX}$ as in Group $\mathrm{BX} \rightarrow \mathrm{AX}$.

The results of the present experiments, therefore, seem to provide strong support for the suggestion derivable from McLaren et al. (1989) that the mechanism underlying the different effects of alternating and blocked preexposure is that alternating preexposure to two com- pound flavors establishes inhibitory associations between their unique elements, and that these inhibitory associations help to explain both the Espinet effect and some instances of perceptual learning. One crucial point, however, needs to be addressed. It is not, after all, immediately obvious why the establishment of inhibitory associations between A and B should then turn B into a conditioned inhibitor of a US that has been paired with $A$. In considering possible explanations of their results, Espinet et al. (1995) suggested that if there was mutual inhibition between $\mathrm{A}$ and $\mathrm{B}$, presentation of one might drive the activation of units representing the other negative. Thus, on conditioning trials to $A$, the representation of $B$ would take on a negative activation, and Espinet et al. suggested that the negative activation of a CS concomitant with the positive activation of a US might be sufficient to turn that CS into a conditioned inhibitor of that US.

Brief reflection, however, should make it clear that this cannot possibly be the explanation of the results of Experiment 3. According to Espinet et al. (1995), the critical inhibitory association must be that from $\mathrm{A}$ to $\mathrm{B}$, but the comparison between Groups $\mathrm{AX} \rightarrow \mathrm{BX}$ and $\mathrm{BX} \rightarrow \mathrm{AX}$ implies that the inhibitory association from $B$ to $A$ is responsible for the "Espinet effect." We must conclude that Espinet et al.'s specific proposal does not provide the correct explanation of their results. An alternative, probably rather simpler analysis is that the Espinet effect arises not on conditioning trials to $\mathrm{A}$, but on summation or retardation test trials to $B$. If the presentation of $B$ inhibits a representation of $A$ and drives the $A$ unit negative, it will also inhibit activation of the representation of any US associated with A.

\section{REFERENCES}

Bennett, C. H., \& Mackintosh, N. J. (in press). Comparison and contrast as a mechanism of perceptual learning? Quarterly Journal of Experimental Psychology.

Bennett, C. H., Wills, S. J., Wells, J. O., \& Mackintosh, N. J. (1994). Reduced generalization following preexposure: Latent inhibition of common elements or a difference in familiarity? Journal of Experimental Psychology: Animal Behavior Processes, 20, 232-239.

BrogdEN, W. J. (1939). Sensory pre-conditioning. Journal of Experimental Psychology, 25, 323-332.

Brown, C. P., \& KING, M. G. (1969). Backward sensory preconditioning: The ineffectiveness of the procedure under optimal conditions. Australian Journal of Psychology, 21, 55-58.

Coppock, W. J. (1958). Pre-extinction in sensory preconditioning. Journal of Experimental Psychology, 55, 213-219.

Dickinson, A., \& BURKE, J. (1996). Within-compound associations mediate the retrospective revaluation of causality judgements. Quarterly Journal of Experimental Psychology, 49B, 60-80.

Espinet, A., Iraola, J. A., Bennett, C. H., \& Mackintosh, N. J. (1995). Inhibitory associations between neutral stimuli in flavoraversion conditioning. Animal Learning \& Behavior, 23, 361-368.

Estes, W. K. (1950). Towards a statistical theory of learning. Psychological Review, 57, 94-107.

EWING, M. F., LAREW, M. B., \& WaGner, A. R. (1985). Distributionof-trials effects in Pavlovian conditioning: An apparent involvement of inhibitory backward conditioning with short intertrial intervals. Journal of Experimental Psychology: Animal Behavior Processes, 11, 537-547. 
GiBSON, E. J. (1969). Principles of perceptual learning and development. New York: Appleton-Century-Crofts.

HALL, G. (1991). Perceptual and associative learning. Oxford: Oxford University Press, Clarendon Press.

Holland, P. C. (1981). Acquisition of representation-mediated conditioned food aversions. Learning \& Motivation, 12, 1-18.

Kleiman, M. C., \& Fowler, H. (1984), Variations in explicitly unpaired training are differentially effective in producing conditioned inhibition. Learning \& Motivation, 15, 127-155.

LuBow, R. E. (1989). Latent inhibition and conditioned attention theory. Cambridge: Cambridge University Press.

Lubow, R. E., WEINER, I., \& SCHNUR, P. (1981). Conditioned attention theory. In G. H. Bower (Ed.), The psychology of learning and motivation (Vol. 15, pp. 1-50). New York: Academic Press.

Mackintosh, N. J., Kaye, H., \& Bennett, C. H. (1991). Perceptual learning in flavour aversion conditioning. Quarterly Journal of Experimental Psychology, 43B, 297-322.

Maier, S. F., Rapaport, P., \& Wheatley, K. L. (1976). Conditioned inhibition and the UCS-CS interval. Animal Learning \& Behavior, 4, 217-220.

McLaren, I. P. L., Kaye, H., \& Mackintosh, N. J. (1989). An associative theory of the representation of stimuli: Applications to perceptual learning and latent inhibition. In R. G. M. Morris (Ed.), Parallel distributed processing: Implications for psychology and neurobiology (pp. 102-130). Oxford: Oxford University Press, Clarendon Press.

PrEwITT, E. P. (1967). Number of preconditioning trials in sensory preconditioning using CER training. Journal of Comparative \& Physiological Psychology, 64, 360-362.

Rescorla, R. A. (1969). Pavlovian conditioned inhibition. Psychological Bulletin, 72, 77-94.

Rescorla, R. A., \& Cunningham, C. L. (1978). Within-compound fla- vor associations. Journal of Experimental Psychology: Animal Behavior Processes, 2, 267-275.

Symonds, M., \& Hall, G. (1995). Perceptual learning in flavor aversion conditioning: Roles of stimulus comparison and latent inhibition of common stimulus elements. Learning \& Motivation, 26, $203-$ 219.

Tait, R. W., Marquis, H. A., Williams, R., Weinstein, L., \& Suboski. M. D. (1969). Extinction of sensory preconditioning. Journal of Comparative \& Physiological Psychology, 69, 170-172.

Van Hamme, L. J., \& Wasserman, E. A. (1994). Cue competition in causality judgements: The role of nonpresentation of compound stimulus elements. Learning \& Motivation, 25, 127-151.

WAGNER, A. R. (1981). SOP: A model of automatic memory processing in animal behavior. In N. E. Spear \& R. R. Miller (Eds.), Information processing in animals: Memory mechanisms (pp. 5-47). Hillsdale, NJ: Erlbaum.

WAGNER, A. R., \& Brandon, S. E. (1989). Evolution of a structured connectionist model of Pavlovian conditioning (AESOP). In B. B Klein \& R. R. Mowrer (Eds.). Contemporary learning theories: Pavlovian conditioning and the status of traditional learning theory (pp. 149-189). Hillsdale, NJ: Erlbaum.

WaGner, A. R., \& Larew, M. B. (1985). Opponent processes and Pavlovian inhibition. In R. R. Miller \& N. E. Spear (Eds.), Information processing in animals: Conditioned inhibition (pp. 223-267). Hillsdale, NJ: Erlbaum.

WARD-Robinson, J., \& HALl, G. (1996). Backward sensory preconditioning. Journal of Experimental Psychology: Animal Behavior Processes, 22, 395-404.

(Manuscript received October 7, 1998; revision accepted for publication November 23, 1998.) 